\title{
Reflexões acerca do conceito de cultura nas pesquisas em História da Educação: o embate entre jesuítas e nativos na América portuguesa do século XVI e XVII.
}

\author{
Reflexiones sobre el concepto de cultura en la investigación en Historia de \\ la Educación: relaciones entre jesuitas y nativos en América del siglo XVI \\ y XVII.
}

\author{
Thoughts on the concept of culture in the History of Education's \\ researches: the clash between Jesuits and natives in Portuguese America \\ of the 16th and 17th century.
}

Leandro Lente de Andrade ${ }^{1}$

\begin{abstract}
Resumo
O presente artigo procura trazer algumas reflexões acerca do uso do conceito de cultura ao se tratar de pesquisa em história cultural na América portuguesa, sobretudo no século XVI e XVII e a relação educacional entre os jesuítas e os nativos. Para isso, será traçado alguns comentários acerca das transformações na definição do conceito de cultura ao longo da história, bem como, no que consistia o termo cultura no período em questão. As representações dos elementos culturais pelos sujeitos que deixaram registros (nas cartas jesuíticas, por exemplo) e a consequente ausência, no período, de um termo que abranja todo o significado que a pesquisa exige. É sugerida uma definição apropriada de cultura a ser adotada e a História Cultural como viés de construção histórica da cultura, a importância de Michel de Certeau e Carlo Ginzburg, assim como a contribuição de Michel Foucault para a análise do discurso. E, por fim, é traçado um paralelo com as recentes tendências nas pesquisas em Educação, tendo em vista as reflexões abordadas no corpo do texto.
\end{abstract}

Palavras-Chave: Cultura, História, Educação, Indígenas, Jesuítas.

\section{Resumen}

Este artículo trata de dar algunas reflexiones sobre el uso del concepto de la cultura cuando se trata de investigar en la historia cultural en la América portuguesa, especialmente en el siglo XVI y XVII y la relación educativa entre los jesuitas y los nativos. Para esto, se puede remontar algunos comentarios acerca de los cambios en la definición de la cultura a lo largo de la historia, y en que consistía el término cultura en el período. Las representaciones de los elementos culturales de los individuos que dejaron registros (en las cartas de los jesuitas, por ejemplo) y la consiguiente ausencia en el período de un término que abarca todo el significado que requiere la investigación. Sugiere una definición adecuada de la cultura que se adoptará y la Historia Cultural como un sesgo de construción histórico de la cultura, la importancia de Michel de Certeau y Carlo Ginzburg, así como la contribución de Michel Foucault para el análisis del discurso. Y, por fin, trazado un paralelo con las recientes tendencias en las investigaciones en Educación, teniendo en vista las reflexiones abordadas en el cuerpo del texto y la relación entre la cultura y la educación, a partir de la contribución de Dominique Julia.

Palabras claves: Cultura, Historia, Educación, Indígenas, Jesuitas.

\footnotetext{
${ }^{1}$ Mestrando em Educação; bolsista do PPGE da Universidade Federal de Alfenas (Unifal-MG); Alfenas, Minas Gerais, Brasil; leeandroandrade@hotmail.com. Extensão do trabalho apresentado no I Seminário LatinoAmericano de Estudos em Cultura - SEMLACult, Foz do Iguaçu/PR, Brasil, 2017.
} 


\begin{abstract}
The present article seeks to bring some thoughts about the use of the concept of culture when dealing with research in cultural history in Portuguese America, especially in the sixteenth and seventeenth centuries and the educational relationship between the Jesuits and the natives. To this end, there are some comments about the transformations in the definition of the concept of culture throughout history, as well as what the term culture in the period proposed consisted of. The representations of cultural elements by the subjects who left records (in the Jesuit letters, for example) and the consequent absence in the period of a term that covers all the meaning that research demands. It is suggested an appropriate definition of culture to be adopted and Cultural History as bias of historical construction of culture, the importance of Michel de Certeau and Carlo Ginzburg, even as the contribution of Michel Foucault to the discourse analysis. Finally, we draw a parallel with the recent trends in education research, in light of the reflections addressed in the body of the text and the relationship between culture and education, based on the contribution of Dominique Julia.
\end{abstract}

Keywords: Culture, History, Education, Indigenous, Jesuits.

\title{
1. Introdução
}

Como se referir às práticas, rituais, costumes e hábitos que transcendem a esfera da aparente mística e adentra nas questões mais profundas do ser, tais como as mentalidades e questões morais de um determinado grupo? Como agrupar todo o conjunto denso e complexo que marca as características desse grupo, sem que haja uma categoria que satisfaça essa demanda? Ou melhor, de que forma abordar tal temática sem cair num anacronismo, apropriando-se da definição de um conceito contemporâneo, quando no passado seu uso possuía outra conotação? E ainda, qual melhor modo de abordar o conjunto de aspetos dos sujeitos presos no passado, recorrendo às fontes que não possuíam finalidade antropológica em seus registros documentais? Estas são algumas das perguntas que permearão as reflexões aqui realizadas. Longe de procurar estabelecer respostas definitivas para as questões propostas, estas reflexões visam contribuir com alguns elementos importantes acerca do conceito de cultura e sua apropriação na pesquisa histórica, tomando como pano de fundo e objeto de estudo o embate entre jesuítas e indígenas no ensino e catequização da América portuguesa do século XVI e XVII.

\section{A Cultura na História}

O significado que atribuímos as palavras está ligado ao contexto em que elas estão inseridas, portanto a transformação desses significados pode variar de acordo com influências sociais e históricas. Tal ramo da linguística vem ressurgindo nas últimas décadas ao tratar da semântica histórica (ROTH, 1998). O conceito de cultura é um dos que passaram por diferentes definições, que sofreram transformações de acordo com o momento histórico e geográfico em que foram empregados. 
Sem pretender me adentrar por toda a história do conceito de cultura, é importante salientar alguns sentidos que ele já possuiu ao longo da história. Os primeiros usos do termo aparecem oriundos do latim cultura, no fim do século XIII, para designar o cuidado na lida com o campo ou gado, basicamente tendo seu uso se referindo à terra cultivada (CUCHE, 2002, p 19). Nos séculos XVI e XVII inicia-se o uso figurativo da palavra cultura, tornando-o complexo e mais frequente a partir do século XVIII, momento no qual surgem as suas relações análogas com o termo civilização e as diferentes definições oriundas do debate franco-alemão que durou até meados do século XX; sendo que, tal debate é "arquétipo das duas concepções de cultura, uma particularista, a outra universalista, que estão na base das duas maneiras de definir o conceito de cultura nas ciências sociais contemporâneas" (ibidem, p. 31). Ademais, há ainda três variações significativas - e mais próximas do século XX - para o conceito de cultura. Terry Eagleton (2005), as classifica como a "crítica anticapitalista", a "plural” e “erudita/artística" (p. 19-30); noções que influenciam diretamente o modo como compreendemos a cultura hoje em dia.

Esta breve introdução tem sua importância, não apenas para entendermos a ideia de cultura presente atualmente em nossa sociedade, mas principalmente, por trazer à pesquisa histórica a ideia de que, nos séculos XVI e grande parte do XVII, o sentido do termo empregado era outro.

No começo do século XVI, ela [a cultura] não significa mais um estado (da coisa cultivada), mas uma ação, ou seja o fato e cultivar a terra. Somente no meio do século XVI se forma o sentido figurado e "cultura" pode designar então a cultura de uma faculdade, isto é, o fato de trabalhar para desenvolvê-la. Mas este sentido figurado será pouco conhecido até a metade do século XVII, obtendo pouco reconhecimento acadêmico e não figurando na maior parte dos dicionários da época. (CUCHE, 2002, p. 19)

Levando em consideração os registros jesuíticos mais explorados pela historiografia brasileira, referentes às culturas dos nativos na América portuguesa dos séculos XVI e XVII, temos três principais jesuítas: Pe. Manuel da Nóbrega, desde a chegada em 1549; Pe. José de Anchieta e Pe. Antônio Vieira, até 1697, ano de seu falecimento. Trata-se, então, de um período de transição na utilização do termo. Ao analisar os documentos primários, sobretudo as cartas jesuíticas, autos anchietanos e sermões de Vieira, o termo cultura não é usado para se referir às representações culturais, que envolvem tanto as práticas e hábitos dos indígenas da América portuguesa, quanto o próprio modus procedendi dos membros da Companhia de Jesus, os quais faziam o registro.

Em suas cartas, podem ser destacados os temas "da antropofagia, da poligamia, da inconstância, da nudez, da guerra, da guerra justa, do aldeamento, da escravização, do ensino de orações e da leitura, da falta de Deus ou de deuses, dos feiticeiros, da língua escura etc.” 
(HANSEN, 1995, p. 91). Além do desconhecimento da religião cristã, e toda teologia que a envolve, os nativos são chamados de "bestas por natureza corrupta" [Diálogo sobre a conversão do gentio, 1556-1557] (NÓBREGA, 2006, p. 9) por não possuem sequer valores morais cristãos básicos conforme Nóbrega afirma em carta:

A lei, que lhes hão-de dar, é defeder-lhes comer carne humana e guerrear sem licença do Governador; fazer-lhes ter uma só mulher, vestirem-se pois têm muito algodão, ao menos despois de christãos, tirar-lhes os feiticeiros, mantê-los em justiça entre si e para com os cristãos; fazê-los viverem quietos sem se mudarem para outra parte, se não for para antre cristãos, tendo terras repartidas que lhes bastem, e com estes Padres da Companhia para os doutrinarem (NÓBREGA, Carta da Baía, 8 de maio de 1558 apud LEITE, 1954, v. II, p. 450).

E ainda, "as cerimônias indígenas resumiam-se, em última instância, ao fenômeno da tentação vitoriosa. O mal se abatia, como uma cobra, sobre os participantes dos cantos, das danças, da cauinagem, do rito antropofágico.” (BOSI, 1992, p. 92). Portanto, as representações culturais indígenas nos documentos não eram classificadas como cultura. Aquilo que podemos chamar de práticas indígenas registradas nas cartas jesuíticas, não compreendem a complexidade necessária que o termo cultura abarca. Por exemplo, a inconstância dos nativos (CASTRO, 2002) recorrente nos registros jesuíticos de Nóbrega e Anchieta (cf. Carta de 1554; ANCHIETA, 1933, p. 47) e muito conhecida pelo "Sermão do Espírito Santo" (1657) de Antônio Vieira, no século posterior, ao fazer a analogia do mármore e da murta. Tal inconstância não é possível ser compreendida se só analisada pelo prisma das práticas, é necessário recorrer a questões mais amplas para compreender os elementos fornecidos pelo conceito de cultura, como a ideia de mentalidade, com o auxílio da psicanálise, por exemplo.

Destarte, consciente de que no século XVI e XVII as representações, do que hoje chamamos por cultura, não eram assim tratadas; ainda há a necessidade da utilização de um termo que englobe, não apenas as práticas, mas as interpretações de significados que elas possam trazer e elementos que não estão inclusos nas expressões utilizadas pelos sujeitos quinhentistas; faz-se necessário a utilização do termo cultura. Tal consciência é fundamental para que, embora seja usado o termo, em suas definições contemporâneas, não haja anacronismo ao se referir aos sujeitos da pesquisa como portadores conscientes da cultura que lhes é atribuída na contemporaneidade. Cabe, então, ao pesquisador, adotar o termo cultura com a finalidade de classificar uma série de elementos que auxiliarão na compreensão daquilo que foi deixado como registro histórico documental. Trata-se de uma ferramenta/categoria que dará base para análise dos sujeitos, deixando que os documentos tragam as informações culturais; e não a tentativa forçada de impor um conceito anacronicamente, sem levar em consideração as particularidades de como as condutas e os fatos se desenrolaram de modo específico no período em questão. 
De modo similar, Denys Cuche justifica o uso do conceito de cultura por etnólogos, mesmo nas sociedades em que tal palavra não existe em seu vocabulário:

\begin{abstract}
A invenção da noção de cultura é em si mesma reveladora de um aspecto fundamental da cultura no seio da qual pôde ser feita esta invenção e que chamaremos, por falta de um termo mais adequado, a cultura ocidental. Inversamente, é significativo que a palavra "cultura" não tenha equivalente na maior parte das línguas orais das sociedades que os etnólogos estudam habitualmente. Isto não implica, evidentemente (ainda que esta evidência não seja universalmente compartilhada!) que estas sociedades não tenham cultura, mas que elas não se colocam a questão de saber se têm ou não uma cultura e ainda menos de definir sua própria cultura. (CUCHE, 2002, p. 17-18)
\end{abstract}

Portanto, tanto o etnógrafo quanto o historiador, podem se apropriar do termo cultura, ainda que as sociedades, os povos ou grupos não possuam algum conceito equivalente, nem tenham consciência de si, enquanto portadores de algo a ser classificado com cultura. Não se trata de transpor, anacronicamente, valores contemporâneos; nem de exigir que os sujeitos quinhentistas possuam como definição o conceito de cultura atual; e, muito menos, julgar os sujeitos (jesuítas) como devastadores da identidade, das tradições, da cultura indígena - ante a valorização da diversidade, própria da nossa sociedade.

A apropriação do termo pelo historiador é necessária para trazer à tona todo um conjunto cultural não evidente, que não está explícito nas representações das fontes primárias; mas que existiu no passado. O desprezo por aquilo que não nos é revelado (e já interpretado) pelas fontes históricas, implica em consentir com o silêncio de uma cultura que não pôde se expressar; e, além disso, correr o risco de perder a possibilidade de um maior saber sobre o passado de um povo e de construir o próprio conhecimento histórico. Portanto,

para o historiador, assim como para o etnólogo, o objetivo é fazer funcionar um conjunto cultural, fazer com que apareçam suas leis, ouvir seus silêncios, estruturar uma paisagem que não poderia ser um simples reflexo sob pena de nada ser. (CERTEAU, 2010, p. 79-80)

Também não se trata de supor elementos culturais avulsos, a priori, sem que haja respaldo das fontes; nem de divagar com base no senso comum as possíveis inferências culturais; mas do esforço do historiador por conjecturar os elos que poderão compor a cultura de um povo, ante a base material que as fontes lhe fornecem.

Deixando clara necessidade do uso do termo cultura como uma categoria na pesquisa, para trazer melhor entendimento para a atual sociedade, diante do significado que hoje lhe é atribuído; é preciso saber como a cultura tem sido abordada por historiadores.

Desde a expressiva obra de Jacob Burckhardt, A cultura do renascimento na Itália, publicada em 1860, a historiografia tem se apropriado do termo sem uma grande preocupação 
em discutir as implicações e questionamentos resultantes desse "empréstimo"² das outras áreas das ciências humanas - da antropologia, no caso. Desde o surgimento de novos paradigmas do "fazer historiográfico", oriundos da aproximação entre a História e as demais ciências, buscando responder novas perguntas acerca do passado, por novos prismas hermenêuticos; ${ }^{3}$ as discussões têm se detido em firmar a História enquanto ciência legítima e nem sempre se preocupam com a viabilidade de tais "empréstimos".

Até então foram tecidos alguns comentários gerais acerca da problemática, visando elucidar um panorama amplo das questões propostas. A partir de agora, detenho-me em afunilar a abordagem, estreitando as reflexões para uma das possíveis definições, abordagens e indicando alguns referenciais teóricos úteis, diante da exigência da pesquisa. ${ }^{4}$

Considerada uma das palavras mais complexas (EAGLETON, 2005, p. 9), tanto por sua transformação no decorrer da história, quanto pela variedade de definições atualmente, o conceito de cultura na pesquisa histórica precisa estar delineado para projetar o conhecimento a ser construído sobre ele e fazer-se entendido por quem irá se apropriar do produto final. Embora sofra severas críticas, uma das definições de cultura que mais influenciaram a historiografia é do antropólogo americano Clifford Geertz, definindo como:

sistemas entrelaçados de signos interpretáveis (o que eu chamaria símbolos, ignorando as utilizações provinciais), a cultura não é um poder, algo ao qual podem ser atribuídos casualmente os acontecimentos sociais, os comportamentos, as instituições ou os processos; ela é um contexto, algo dentro do qual eles podem ser descritos de forma inteligível — isto é, descritos com densidade. (GEERTZ, 2008, p. 10)

Tal definição de cultura semiótica, ${ }^{5}$ apesar de ampla, é bem definida, e apropriada por lidar com os padrões de significados incorporados aos símbolos, que o homem pode atribuir de forma

\footnotetext{
${ }^{2}$ Segundo Burke (1997), "tudo o que os historiadores [...] pareciam desejar de sua disciplina vizinha era a oportunidade de sobrevoá-la, de tempos em tempos, em busca de novos conceitos"; ou, então, na busca por um "casamento" entre as disciplinas, resultando na união os termos, como "antropologia histórica" ou de "etnohistória" (p.94). Sobre este movimento da historiografia em direção as demais disciplinas, em vista de trazer uma compreensão cultural (ou suas extensões: história das mentalidades ou psicologia histórica), Chartier (2002b) pontua o distanciamento "tanto da antiga história intelectual literária como da hegemônica história econômica social", em contrapartida, tomando "de empréstimo às disciplinas vizinhas: [...] linguística e semântica, dos meios estatísticos utilizados pela sociologia ou de alguns modelos da antropologia" (p. 15).

${ }^{3}$ Por exemplo: a história "vista de baixo". Tais aproximações, mencionadas acima, ocorreram entre as décadas de 60, 70 e 80, principalmente na França, com a Escola dos Annales, e na Inglaterra, com a influência de Edward Thompson e Christopher Hill, pelo viés marxista.

${ }^{4}$ A definição e referenciais teóricos que seguem o texto são os que procurei me apropriar para conduzir minha pesquisa. Isso não significa que as respostas apresentadas no decorrer do texto sejam as únicas possíveis, de forma dogmática, mas compreende um dos caminhos a serem trilhados pela pesquisa histórica que busque ressaltar a cultura.

5 "O conceito de cultura que eu defendo [...] é essencialmente semiótico. Acreditando, como Max Weber, que um homem é um animal amarrado a teias de significados que ele mesmo teceu, assumo a cultura como sendo essas teias e sua análise; portanto, não como uma ciência experimental em busca de leis, mas como uma ciência
} 
inteligível e comunicável, e historicamente transmitidos. Além de que valorizar a abordagem da descrição densa dos fatos é algo que torna o entendimento cultural passível de maior compreensão, levando em consideração questões que aparentemente não são tratadas como importantes, mas que no final das contas farão a diferença em como a cultura deverá ser interpretada.

Agora, como realizar uma abordagem histórica de uma determinada cultura? Conforme visto anteriormente, quando se trata de um estudo cultural histórico o pesquisador está preso ao que as fontes secundárias ou primárias têm a fornecer. Diferente do etnógrafo, que pode estar em contato direto com os sujeitos que pretende estudar, o historiador tem o desafio de extrair dos registros (que de modo geral não possuem as finalidades de descrever e elucidar elementos culturais) os aspectos que transparecem uma determinada cultura. Para tanto, uma pesquisa no ramo da história, que leve em consideração diferença entre culturas, respeitando o local do outro e sua distância temporal, que reconheça a lacuna que separa o pesquisador dos sujeitos de sua pesquisa e busque entender, por meio de textos, documentos, cartas e demais fontes primárias, como é a cultura do outro; além de, dialogar com os demais campos de produção de conhecimento que auxiliarão neste processo de construção da representação das práticas e culturas; tal pesquisa exigiria um referencial teórico que possuísse tais características. Acredito que a escola francesa nos Annales tem muito a contribuir, e Michel de Certeau ${ }^{6}$ se enquadra nos parâmetros que a pesquisa exige.

Apesar de, como afirma Roger Chartier, Michel de Certeau não "gostasse muito de se definir, nem de encerrar o que fazia em uma dessas categorias disciplinares que os universitários, como que para se tranquilizar, gostam tanto de reivindicar" (CHARTIER, 2002, p. 151). A maneira de investigação de Certeau pode enquadrá-lo (entre outras classificações) como um "historiador das diferenças"; que busca, partindo do encontro com a estranheza do outro, a compreensão do significado que as fontes podem revelar.

Para ele, fazer a história era ao mesmo tempo submeter à experimentação crítica os modelos forjados em outros contextos, quer fossem sociológicos, econômicos,

interpretativa, à busca de significado" (GEERTZ, 2008, p. 4). Laura de Mello e Souza (1998, p. 18, 37-38) também adota tal definição em seu ensaio Aspectos da historiografia da cultura sobre o Brasil Colonial, justamente pela definição ampla e tratar a ideia de cultura como um contexto (p. 418).

${ }^{6} \mathrm{O}$ conceito de cultura em Certeau parece estar de acordo com a definição de Geertz. O que para o antropólogo americano são "signos interpretáveis", além dos símbolos em si, mas dos significados que tais "sistemas entrelaçados de signos" possam ter para quem os interpreta. Não são, portanto, apenas as práticas humanas, mas os significados atribuídos a elas. Segundo Certeau (2010), "se é verdade que qualquer atividade humana possa ser cultura, ela não o é necessariamente ou não é ainda forçosamente reconhecida como tal. Para que haja verdadeiramente cultura, não basta ser autor de práticas sociais; é preciso que essas práticas sociais tenham significado para aquele que as realiza" (p. 141). 
psicológicos ou culturais, e mobilizar, para entender o sentido dos signos guardados pelo arquivo, suas competências de semiótica, de etnólogo, de psicanalista. (ibidem, p. 152)

Veja que as considerações se complexificam na medida em que há o reconhecimento a complexidade dos sujeitos descritos pelas fontes; exigindo, portanto, uma erudição por parte do pesquisador. Tal perspectiva pode ser encontrada em seus trabalhos sobre a religiosidade cristã na Europa moderna, que vão dos estudos sobre os jesuítas Favre e Surin, na França, a "La Fable mystique, XVI-XVII" e "La Possession de Loudun”. O fato de Certeau ter sido um cristão jesuíta que estudou antigos cristãos jesuítas fez com que o exame dos documentos passasse por uma análise delicada diante das diferenças apresentadas. Vê-se em Certeau, algo como o que em antropologia classifica-se como "estranhamento", a perplexidade diante da percepção da alteridade, no contato com as diferenças culturais; acarretando, para o pesquisador, a necessidade de suspender os seus pressupostos, perspectivas, juízos e valores na abertura para o conhecimento do outro. Certeau, ao identificar o eu, pesquisador, e o outro, inacessível atualmente, mas que está presente nos arquivos; parece reconhecer tal necessidade diante de sua inquietação:

À força de examinar essas folhas de papel enegrecida por uma poeira multicentenária; à força de fichar um vocabulário desarticulado; à força de ser um eruditoimprovisador [bricoleur], nas regiões silenciosas de Arquivos Municipais e Departamentos; à força de habitar nas salas de consultas das Bibliotecas, grotas em que se "conserva" e veicula os cadáveres de outrora; à força de ler, sem nunca ser capaz de entendê-las, palavras que se referem a experiências, doutrinas ou situações estranhas - eu assistia ao afastamento progressivo do mundo, cujos vestígios eram inventariados por mim. Ele me escapava ou, de preferência, eu começava a perceberme de que ele me escapava. Deste momento escalonado incessantemente no tempo, é que tarda o nascimento do historiador. Essa ausência é que constitui o discurso histórico. A morte do outro coloca-o fora de alcance e, por isso mesmo, define o discurso da historiografia, ou seja, do texto histórico. (CERTEAU, 2011, p. 164)

A partir do encontro com o outro, do "estranhamento", e da abertura para a compreensão de novos significados culturais - nem sempre evidentes para sua cultura - é que o historiador exerce seu trabalho. É ao se deparar com o passado, que não existe mais, que o pesquisador tem a tarefa de, consciente da diferença entre o passado e o presente, construir, com base nos documentos, o "seu" passado, estruturado pelo passado verificável nos documentos.

"Faço história" no sentido em que não só produzo textos historiográficos, mas tenho acesso, por meu trabalho, à consciência de que algo se passou, atualmente morto, inacessível como vivo. A estrutura [do passado, por meio dos documentos] defende e exprime esta aquisição da experiência histórica; ela diz que houve algo diferente. [...] A "estrutura" é um conceito-ferramenta que exprime, à semelhança de uma resistência, a diferença que o trabalho histórico faz aparecer entre um presente e "seu" passado. (Ibidem, p. 166-167)

Então, para Certeau a pesquisa no campo da história não é uma reconstrução do passado; mas uma construção do pesquisador em contato com suas fontes. Tal definição pode 
ocorrer no equívoco de concluir que os resultados das pesquisas serão subjetivos, contudo, como defende Roger Chartier:

\begin{abstract}
a história não pode ser considerada, com efeito, como pura retórica ou tropologia que faria dela uma ficção, semelhante a outras ficções. Ela pretende ser um discurso de verdade, construindo uma relação, que pretende ser controlável, com o que estabelece como seu referente, no caso, a "realidade" desaparecida a ser resgatada e compreendida (CHARTIER, 2002, p. 159)
\end{abstract}

Especificamente no recorte da América portuguesa dos séculos XVI e XVII, compreendendo a complexidade das relações culturais dos jesuítas e os nativos, além de exigir erudição em certa medida, o pesquisador não deve se prender à nenhuma estratificação social pré-concebida, nem algum modelo pronto que vise classificar o outro como pertencente a determinado grupo já antes ideado. Fato que poderia causar um reducionismo danoso para a compreensão históricocultural. Sobre esse recorte social construído previamente, Chartier salienta:

É necessário, creio eu, recusar essa dependência que relaciona as diferenças nos hábitos culturais a oposições sociais dadas a priori, seja na escala de contrastes macroscópicos (entre as elites e o povo, entre os dominadores e os dominados), seja na escala de diferenciações menores (por exemplo, entre os grupos sociais hierarquizados pelos níveis de fortuna e as atividades profissionais). (Ibidem, p. 68)

E continua fazendo distinção das representações da história cultural francesa, irrestritas ao caráter econômico (comumente de tradição marxista clássica, por exemplo); e atenta a percepção da composição cultural particular dos sujeitos: ${ }^{7}$

Trabalhando sobre as lutas de representações, cujo objetivo é a ordenação da própria estrutura social, a história cultural afasta-se sem dúvida de uma dependência demasiado estrita em relação a uma história social fadada apenas ao estudo das lutas econômicas, mas também faz retorno útil sobre o social, já que dedica atenção às estratégias simbólicas que determinam posições e relações e constroem, para cada classe, grupo ou meio, um "ser-percebido" constitutivo de sua identidade (Ibidem, p. 73)

O esforço de Michel de Certeau em realizar uma historiografia que dê atenção ao outro, levantando elementos culturais ainda não percebidos, e que dê espaço para que as fontes revelem a cultura a ser percebida e conduzam o pesquisador, sem que hajam imposições $a$ priori; pode ser aproximado das investigações do historiador italiano Carlo Ginzburg (FERNÁNDEZ, 2014, p. 156).

A pesquisa na qual propõe-se a reflexão deve dar importância a alguns elementos que ainda não receberam a atenção que merecem. Elementos que certamente poderão contribuir na pesquisa, tomando uma configuração investigativa dos documentos. Assim, Ginzburg é outro exemplo de abordagem e de uma possibilidade como aporte teórico. O historiador italiano

\footnotetext{
${ }^{7}$ Apenas a título de exemplo, vale mencionar John W. O’Malley, outro jesuíta com expressão no meio acadêmico, por sua abordagem partir da investigação de "quem, eles mesmos, entendiam ser?", visando ter conhecimento da autocompreensão que a Companhia de Jesus tinha (O'MALLEY, 2004, p. 19). Sendo assim, suas pesquisas são exemplos de compreensão cultural, por meio dos documentos históricos.
} 
realiza seus trabalhos nessa área, classificada como micro-história. Obras como "O queijo e os vermes", "História noturna" e "Os andarilhos do bem", são alguns exemplos do método que dá atenção aos detalhes, as minúcias e a investigação das fontes documentais primárias, que podem revelar muitas tendências daquilo que não se está explicitamente registrado de forma escrita. Em "O queijo e os vermes", Ginzburg analisa os documentos do Tribunal do Santo Ofício colocando, literalmente, "o inquisidor como antropólogo" - título de um de seus artigos. No capítulo "Sinais: raízes de um paradigma indiciário", de sua obra "Mitos, emblemas, sinais: Morfologia e História", Ginzburg sintetiza:

modelo epistemológico (caso prefira paradigma) ao qual até agora não se prestou suficiente atenção. A análise desse paradigma, amplamente operante de fato, ainda que não teorizado explicitamente (GINZBURG, 1989. p. 143)

Para isso, traz, de forma clara, três grandes exemplos: Freud, na metodologia de anotar cada fragmento de pensamento dos envolvidos em sua psicanálise; Morelli, na atenção aos traços que fariam distinção entre as obras de arte falsas, originais e cópias; e, também, o escritor Arthur Conan Doyle, e seu famoso personagem Sherlock Holmes. Assim, Carlo Ginzburg tem também muito a contribuir com as intenções que um estudo cultural histórico possui. Pois o paradigma indiciário certamente auxilia na investigação e descoberta de novas informações relevantes que envolvem as práticas, pois "a história das práticas culturais é, com efeito, a mais difícil de se reconstruir porque ela não deixa traço: o que é evidente em um dado momento tem necessidade de ser dito ou escrito?” (JULIA, 2001, p. 15). Sendo assim, diante da ausência explícita de informações, qualquer mero detalhe pode se tornar uma pista importante para a pesquisa.

No livro "História: a arte de inventar o passado", de Durval Muniz de Albuquerque Júnior (2007), há um interessante capítulo destinado a duas possibilidades do uso do paradigma indiciário:

Foucault e Ginzburg identificam o surgimento, no final do século 19, de um novo paradigma no campo das Ciências Humanas, o paradigma indiciário. Este operaria através de sinais, sintomas, ou seja, indícios que serviriam para uma aproximação ou apropriação do real, como pretende Ginzburg, ou para a partir deles se construir o real, como quer Foucault. Aí está explicitada uma diferença fundamental entre os dois autores. Embora operem com mesmo paradigma, fazem-no de forma diferenciada. Enquanto Ginzburg opera com os indícios históricos com a pretensão de ser possível de reconstrução do real em sua totalidade, mesmo que essa reconstrução seja sempre atravessada pela subjetividade do historiador e datada historicamente, Foucault parte do pressuposto de que o real é uma construção discursiva, feita tanto no passado como

\footnotetext{
${ }^{8} \mathrm{O}$ livro reúne uma coletânea de artigos, distribuídos em capítulos, relacionados a Teoria da História/Filosofia da História. O artigo que faço referência é "Menocchio e Rivière: criminosos da palavra, poetas do silêncio". As obras trabalhadas no artigo podem ser classificadas dentro da "micro-história". Menocchio foi um moleiro italiano do século XVI condenado pela Inquisição por suas ideias contrariarem as doutrinas católicas, estudado por Ginzburg. Pierre Rivière foi um camponês francês do século XIX assassino confesso de sua mãe e irmãos, estudado por Foucault.
} 
no presente. O historiador não pode tomar os documentos, as fontes históricas, como indícios de um real que pode ser desvendado, um real que estaria nas entrelinhas e seria reconstruído pelo historiador. Para ele, a fonte histórica é sempre um monumento, ou seja, uma construção também histórica e discursiva. Ela não é sinal de um acontecimento, como quer Ginzburg, embora se remeta a um acontecimento que deve ser explicado. (p. 102-103)

As duas abordagens divergem substancialmente a partir do olhar que é dado para as fontes. Foucault toma a fonte como um discurso fruto de pressões externas que delimitam o sujeito e fazem-no discorrer dentro do quadro no qual está inserido e circunscrito pelos procedimentos externos e internos de controle e de delimitação do discurso (FOUCAULT, 2009). Diante disso, o paradigma indiciário possui o viés de investigar qual é a realidade que se impõe ao discurso. Ginzburg, por sua vez, encara a fonte como representante do real. Partindo desse pressuposto, busca atribuir sentido ao que pode ser inferido a partir do que as fontes relatam. Para Foucault a fonte é o produto final do conjunto histórico, para Ginzburg é o início do fazer historiográfico.

Embora parta do paradigma indiciário, Foucault não faz uma semiologia do visível, das iluminações apenas, os sinais não são tomados por ele como fragmentos de um real a ser reconstituído como faz Ginzburg; para ele, os próprios indícios ou sinais são construções, eles não são deixados por acaso. Antes de se perguntar o que fez com que eles representassem esse real, deveria se perguntar que estratégias de poder e que relação do poder-saber foram responsáveis pela construção destes sinais. Com eles pode-se construir um novo real a partir das demandas de poder-saber colocadas como monumentos históricos. (ALBUQUERQUE JÚNIOR, 2007, p. 110)

Uma leitura apresada dos dois autores pode nos remeter a uma unilateralidade ante o mesmo paradigma, em que um viés de abordagem anule o outro. Mas, não necessariamente. Ao meu ver, ambas as abordagens poder ser complementares, ante o mesmo paradigma. Peguemos, por exemplo de uma carta jesuítica do século XVI. Uma leitura foucaultiana procuraria mapear em qual ambiente histórico produziria o discurso presente no conteúdo da carta; os poderes atuantes que exerceriam poder no sujeito, escritor da carta, pelos procedimentos externos (ex.: a interdição; ${ }^{9}$ as instituições: a Igreja Católica, a Ordem Companhia de Jesus, a Coroa Portuguesa etc.) e internos (ex.: recorte do indivíduo como autor singular, a dimensão de inserção temporal do indivíduo em seu discurso etc.). Enfim, revelaria os componentes de poder, que exercem influência na cultura jesuítica; bem como a própria cultura dos jesuítas. Por

\footnotetext{
${ }^{9}$ Por algumas vezes, os próprios autores das cartas jesuíticas revelam, explicitamente, a inadequação da realidade para ser expressa em suas cartas. Pe. Nóbrega relata em carta destinada ao Pe. Simão Rodrigues, em 1550, que como resultado da "mercancia" entre os cristãos e os gentios, os índios, "nascen da parte destes tantas cousas illicitas e exorbitantes que nunca as poderei escrever" (NÓBREGA, 1931, p. 108). De modo semelhante, Pe. Anchieta escreve em junho de 1560: "Ay tan poças cosas dignas de se escrivir que no sé que escriva, porque si espera V. P. que aya muchos de los Brasilles convertidos enganarse a su esperança, porque los ya adultos, a los quales la mala costumbre de sus padres se les a quasi convertido en naturaleza, cierran las orejas para no oir la palabra de salud y converterse al verdadero culto de Dios" (LEITE, 1958, v. III, p. 249).
} 
outro lado, a perspectiva ginzburgiana, sobre a mesma carta, procuraria investigar os elementos ali - no conteúdo da carta - representados, tais como a cultura indígena. Portanto, cabe ao pesquisador a realização do exercício da mudança de perspectiva sobre a mesma fonte. Ao meu ver, os diferentes olhares sobre a fontes, não são, necessariamente, excludentes (desde que fiquem claras as transições conscientes entre as perspectivas).

Neste momento é importante fazer uma ponderação. $\mathrm{O}$ anseio por desempenhar seu papel $^{10}$ em extrair dos documentos as culturas envolvidas na pesquisa, o estudioso corre o risco de revelar mais de si e dos seus pressupostos, sejam eles éticos, políticos, religiosos, entre outros, ${ }^{11}$ do que das questões que estavam em pauta no contexto histórico da época. ${ }^{12}$ Sobre esse risco, Certeau (2010) adverte:

seria um erro acreditar que esses instrumentos [atentos à cultura] sejam neutros e seu olhar, inerte: nada se oferece, tudo pode ser tomado, e a mesma violência da interpretação pode aqui criar ou suprimir. A mais ambiciosa das nossas obras, a mais audaciosa é também a menos histórica e aquela que certamente mais deixa escapar seu objeto quando pretende submetê-lo ao fogo convergente de uma série de interrogações (literária, folclorista, linguística, histórica, psicanalítica etc.) (p. 79-80)

Todavia, o mesmo ecletismo que auxilia na compreensão de uma determinada cultura, pode fazer com que os próprios sujeitos da pesquisa percam o protagonismo e transfira os holofotes para o pesquisador e suas afeições. Nesses casos,

em última análise, o estudo informa-nos menos sobre a cultura popular do que sobre aquilo que é, para um universitário progressista de hoje, fala da cultura popular. Isto nos remete a uma questão com a que deparamos repetidas vezes e à qual é preciso responder: de onde se fala, o que se pode dizer? Mas também, enfim: de onde falamos nós? O problema torna-se, por conseguinte, imediatamente político, uma vez que coloca em causa a função social - isto é, antes de mais nada repressivo - da cultura erudita. (CERTEAU, 2010, p. 80)

Esse é um dos problemas no qual o pesquisador das ciências humanas, de modo geral, deve lidar. O local de onde se levantam questões, ditas pertinentes, e se critica a antiga postura de uma vertente anterior a atual; será alvo de críticas no futuro. Não há como fugir da linguagem que nos cerca, que cerca o pesquisador. Ele fala partindo das suas inquietações, as quais estão presas no chão que ele pisa, no anseio por buscar a compreensão de algo do passado - como é o caso da pesquisa em História - ainda que para isso seja necessário fundar um saber

\footnotetext{
${ }^{10}$ Para Certeau (2010), "é no momento em que uma cultura não mais possui mais os meios de se defender que o etnólogo ou o arqueólogo aparece" (p. 61)

11 "Como afirmam Hayden White, Michel de Certeau e Paul Veyne, a escolha de uma opção teórica metodológica em História não se dá porque tal o qual teoria é mais científica, oferece melhor acesso à verdade ou ao real, mas apenas por melhor atender a pressupostos éticos, morais, religiosos, filosóficos ou políticos diferenciados entre os historiadores." (ALBUQUERQUE JÚNIOR, 2007, p. 236)

${ }^{12}$ Sem tirar o mérito da importância do autor e da obra, gostaria de exemplificar a imposição de pressupostos e uma leitura, ao meu ver, anacrônica da atuação jesuítica sob uma hermenêutica superestrutural, é a obra de Aníbal Ponce, Educação e Luta de Classes, capítulo V, A educação do homem burguês.
} 
"violentando" o passado (CERTEAU, 2010, p. 81). De qualquer forma, a "inquietante interrogação" permanece e a consciência dos problemas a serem enfrentados tem sua importância para que o pesquisador não desempenhe sua função de modo descuidado.

\section{A História Cultural na Educação}

Foram tratadas, até aqui, algumas problematizações da pesquisa histórica que se arrisca enveredando-se pela cultura no seu sentido amplo, sem o recorte da educação jesuítica no século XVI e XVII em sua relação com os indígenas da América portuguesa. Foram feitas poucas menções, dentre as quais tiveram caráter de exemplificar o assunto tratado, aos sujeitos e ao objeto da pesquisa; porém, a teoria apresentada não está distante do recorte da pesquisa como, talvez, possa parecer. Passo agora a afunilar a minha abordagem desta relação história-cultura, inclinando-a para uma das dimensões culturais, a educação.

A educação, por sua vez, que reverbera aspectos da cultura e, também, exerce papel ativo na cultura, quer perpetuando-a, quer modificando-a; ou participando diretamente para a manutenção de uma hegemonia cultural, ou servindo como motor de uma transformação sociocultural, ou, ainda, tornando-a hibrida. A vista de uma pesquisa histórica na área de Educação é importante ter em mente que os conceitos, que hoje são empregados em pesquisas voltadas para as atuais práticas escolares e aplicadas ao cotidiano da sociedade em que vivemos, não possuem as mesmas definições. O conceito de cultura escolar que penso ser adequado para tal pesquisa é definido

como um conjunto de normas que definem conhecimentos a ensinar e condutas a inculcar, e um conjunto de práticas que permitem a transmissão desses conhecimentos e a incorporação desses comportamentos; normas e práticas coordenadas a finalidades que podem variar segundo as épocas (finalidades religiosas, sociopolíticas ou simplesmente de socialização) (JULIA, 2001, p. 10, grifos meus).

Os destaques realizados na citação são referentes aos enfoques específicos do embate entre jesuítas e indígenas, priorizando a finalidade das intervenções educacionais jesuíticas em suas relações com os nativos; ou seja, ajudar as almas e a conversão dos pagãos. Diante dessa finalidade religiosa, as práticas visarão uma transformação da conduta, "inculcação dos comportamentos" (Ibidem, p. 22) que deverão obedecer a moral cristã católica. Sendo assim, a cultura a ser trabalhada na educação jesuítica em seu contato com os nativos não se restringe ao âmbito interno escolar, ${ }^{13}$ mas passa por aquilo que pode ser classificado como cultura

\footnotetext{
${ }^{13}$ A educação jesuítica no campo missionário não está presa às estruturas físicas, dos colégios, direcionada aos filhos dos colonos; mas a educação nos ambientes mais informais. Baêta-Neves (1978) faz uma classificação entre educação institucional e não institucional no período. Segundo essa divisão, minha pesquisa se enquadra na educação informal. Contudo, gostaria de ressaltar que tais divisões e categorias distintas não possuem a finalidade
} 
escolar. Resumidamente, as culturas externas ao ambiente escolar - sobretudo advindas da Europa - influenciaram o modo como ocorreu a cultura escolar interna, que, por sua vez, tiveram seu "eco" na cultura externa - no modus procedendi jesuíta com os nativos. Em outras palavras, o embate cultural ocorre com influências externas, finalidades externas, resultados externos; e, por meios e práticas advindas do ambiente interno, que envolvem a cultura escolar, a serem adaptadas de acordo com as necessidades. Por quanto, conclui que se tratando das práticas jesuíticas, não há como conceber uma cultura escolar "como um mundo fechado, fechado dos ruídos do exterior" (Ibidem, p. 23).

Tendo em vista esses paradigmas e o viés interpretativo da História Cultura, a pesquisa em História da Educação faz-se parte integrante da busca por entender a cultura pelo viés do que Faria Filho (2002, p. 110), classifica como um "novo olhar", visando ressaltar a interdisciplinaridade cooperativa na análise da educação e suas dimensões culturais. A respeito disso, afirma:

um novo olhar que, ao acolher as contribuições de vários autores, tem permitido, além de um diálogo com vários historiadores e estudiosos de outros campos, como da antropologia, da sociologia, da filosofia, da linguística, uma ampliação do repertório dos estudos sobre a escola e o seu processo de institucionalização na realidade brasileira. (GONÇALVES; FARIA FILHO, 2005, p. 33)

Assim, a abordagem não será unilateral, mas procurará se apropriar de diversos autores e de uma diversidade conceitual que colaborarão para a compreensão e auxiliarão no decorrer da pesquisa; pois, "trabalhar com essa pluralidade interdisciplinar somente poderá contribuir para um melhor entendimento da prática escolar" (Ibidem, p. 39).

É ressaltando essa complexidade das questões referentes aos estudos culturais, que exigem um diálogo entre várias áreas do conhecimento que pretendo finalizar as reflexões. A capacidade de estabelecer pontes entre as disciplinas, relacionar os saberes desenvolvidos por áreas que não estão diretamente vinculadas, serão exercícios recorrentes na pesquisa em história da educação e exigirão certa erudição por parte do pesquisador; mas que, certamente fará de seu produto final algo relevante, tanto para o meio acadêmico, quanto para a contribuição e engajamento das questões culturais no saber popular de temas complexos. ${ }^{14}$

de representar algo que existia consciente e propositalmente pelos jesuítas quinhentistas em solo brasílico, mas possuiu o objetivo de elucidar a distinção dos ambientes de atuação da Companhia de Jesus. Nesse sentido, uma das principais características da Ordem é a de adaptação, da flexibilidade e da capacidade de elaborar meios para atingir suas finalidades, independente do contexto em que estivessem inseridos; portanto, para o jesuíta, sua missão era una e não encontramos na documentação do período a divisão que a historiografia tem feito para definir os diferentes tipos atuação educacional jesuítica.

14 Ao fim dessa seção, gostaria de salientar que as reflexões presentes aqui formam um panorama geral das contribuições que penso ser útil para a pesquisa, mediante as necessidades que possam aparecer. E, embora traga 


\section{Considerações finais}

As reflexões aqui presentes pretendem colaborar para as discussões da inserção da esfera cultural nas abordagens históricas, eixo pouco explorado na historiografia da educação brasileira e nas discussões teóricas. Obviamente, diversas outras possibilidades são admitidas. O tema é vasto. Não tem-se a pretensão de esgotar o tema em tão poucas palavras, nem estabelecer tais reflexões como parâmetros cabais do uso do conceito de cultura, tampouco de paradigmas que valorizem tal abordagem. Porém, espera-se que contribua para as discussões, auxilie os novos pesquisadores da área e suscite novas reflexões acerca da relação entre Cultura e História.

\section{Referências}

ANCHIETA, José de. Cartas: informações, fragmentos históricos e sermões do Padre Joseph de Anchieta. S. J. (1554-1594). Rio de Janeiro: Civilização Brasileira, 1933

BOSI, Alfredo. Dialética da Colonização. São Paulo: Companhia das Letras, 1992.

BURKE, Peter. A Escola dos Annales: a revolução francesa da historiografia (1929 - 1989). São Paulo: UNESP, 1997.

CASTRO, Eduardo Viveiros de. A inconstância da alma selvagem e outros ensaios de antropologia. São Paulo-SP: Cosac \& Naify, 2002.

CERTEAU, Michel de. A cultura no plural. 6ª ed. Campinas: Papirus, 2010.

. A invenção do cotidiano. $3^{\mathrm{a}}$ Ed. Petrópolis-RJ: Editora Vozes, 1998.

. História e psicanálise: entre ficção e realidade. Tradução: Guilherme João de Freitas Teixeira. Belo Horizonte:MG: Autêntica Editora, 2011.

CHARTIER, Roger. À beira da falésia: a história entre certezas e inquietude. Cap. 2 e 6. Porto Alegre: Ed. Universidade/UFRGS, 2002.

CUCHE, Denys. A noção de cultura nas ciências sociais. $2^{\text {a }}$ Ed. Bauru-SP: EDUSC, 2002.

EAGLETON, Terry. A ideia de cultura. São Paulo: Editora UNESP, 2005.

FARIA FILHO, Luciano Mendes de. Escolarização, culturas e práticas escolares no brasil: elementos teórico-metodológicos de um programa de pesquisa. In: LOPES, A. A. B de M.;

algumas respostas, não há a pretensão de colocá-las como $o$ caminho, mas um dos caminhos. Isso significa que os critérios adotados para uma abordagem histórica, que tomem a cultura como um viés de abordagem, não são uma regra para as pesquisas em História, ou História da Educação; e que o paradigma metodológico não é algo fixo para a pesquisa. 
GONÇALVES, I. A.; FARIA FILHO, L. M. de; XAVIER, M de C. (orgs.) História da educação de Minas Gerais. Belo Horizonte: FCH/FUMEC, 2002.

FERNANDÉZ, María Cecilia. Ginzburg y De Certeau: las relaciones entre classe y cultura em el estúdio de las culturas populares. In: Oficios Terrestres, año 20 - Vol.30 - nº 30, p.151-159, Enero-Junio, 2014.

GEERTZ, Clifford. A interpretação das culturas. Cap. 1. Rio de Janeiro-RJ: LTC, 2008.

GINZBURG, Carlo. Sinais: raízes de um paradigma indiciário. p. 143-179 In: . Mitos, emblemas, sinais: morfologia e história. São Paulo: Companhia das Letras, 1989.

HANSEN, João Adolfo. O nu e a luz: cartas jesuíticas do Brasil. Nóbrega - 1549 - 1558. Rev. Inst. Est., SP, 38:87-119, 1995.

JULIA, Dominique. A cultura escolar como objeto histórico. p. 9-43. In: Revista Brasileira de História da Educação, nº 1, jan./jun., 2001.

LEITE, Serafim. Cartas dos primeiros Jesuítas do Brasil. São Paulo, Comissão do IV Cent. da Cid. de São Paulo, v II. 1954.

Monumenta Brasiliae v. III (1558-1563) Roma: Monumenta Historica Societatis Iesu, 1958.

NÓBREGA, Manuel da. Cartas Jesuíticas v. I: Cartas do Brasil (1549-1560). Rio de Janeiro: Officina Industrial Graphica, 1931.

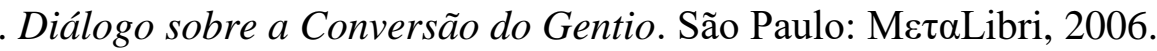

ROTH, Wolfgang. A semântica histórica: um campo abandonado da linguística? In: Rev. Filologia e Linguística Portuguesa, n. 2, p. 61-79, 1998 